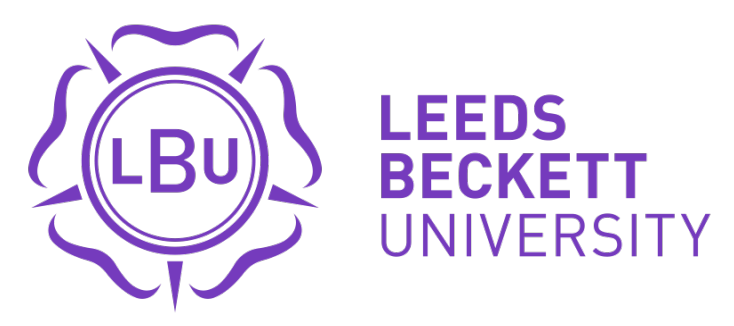

Citation:

Taylor, S (2021) Channelling the darkness: Group flow and environmental expression in the music of Black Sabbath and Joy Division. Metal Music Studies, 7 (1). pp. 85-102. ISSN 2052-3998 DOI: https://doi.org/10.1386/mms_00033_1

Link to Leeds Beckett Repository record:

https://eprints.leedsbeckett.ac.uk/id/eprint/7601/

Document Version:

Article (Accepted Version)

(C) Taylor, S, 2021. The definitive, peer reviewed and edited version of this article is published in Metal Music Studies, 7(1), 85-102, 2021, 10.1386/mms_00033_1

The aim of the Leeds Beckett Repository is to provide open access to our research, as required by funder policies and permitted by publishers and copyright law.

The Leeds Beckett repository holds a wide range of publications, each of which has been checked for copyright and the relevant embargo period has been applied by the Research Services team.

We operate on a standard take-down policy. If you are the author or publisher of an output and you would like it removed from the repository, please contact us and we will investigate on a case-by-case basis.

Each thesis in the repository has been cleared where necessary by the author for third party copyright. If you would like a thesis to be removed from the repository or believe there is an issue with copyright, please contact us on openaccess@leedsbeckett.ac.uk and we will investigate on a case-by-case basis. 
Channelling the Darkness: Group Flow and Environmental Expression in the Music of Black Sabbath and Joy Division

\begin{abstract}
:
Although they superficially belong to different genres of music, Black Sabbath and Joy Division share a fundamental commonality in that their music was shaped by - and powerfully depicted bleak urban-industrial environments. This paper highlights a number of specific ways in which both bands' music depicted (and was influenced by) this environment, including an unusually bass heavy sound, the repetitive and continuous quality of their music, an austerity of sound, the rigid structure of songs and performances and lyrical content. Both bands attained such a high - or pure - degree of environmental expression because they were examples of the phenomenon of 'group flow.' I examine the aspects of group flow identified by psychologists, and show how both bands exhibited these, including a highly cooperative creative process, a lack of conscious deliberation and a prolific and spontaneous output. It was their group flow that enabled the two bands to 'channel' their environment directly and powerfully.
\end{abstract}

Keywords: Black Sabbath, Joy Division, industry, heaviness, creativity, group flow

Scholars have established a connection between urban life and certain forms of music, including heavy metal (Gillet, 1994; Lashua, Spracklen \& Wagg, 2014). This article extends this discussion by focusing specifically on two British bands, Black Sabbath and Joy Division, and offering a detailed analysis of how their music was an expression of the bleak urban environment of England in the 1960s and 1970s. The article connects this environmental expression to the phenomenon of 'group flow,' arguing that this phenomenon enabled both bands to channel their environment directly and powerfully.

The concept of 'flow' was originally developed the psychologist Csikszentmihalyi (1990), referring to a state of intense absorption in which an individual loses awareness of themselves and their surroundings. Flow arises through the focussing of attention on a stimulating and challenging activity and generates a state of enhanced well-being and creativity (Csikszentmihalyi, 1990). In recent years, psychologists have become increasingly interested in the communal aspects flow (e.g. Sawyer, 2007; Walker, 2010; Engeser, 2012; van den Hout, 2018), referring to the phenomenon 
variously as 'social flow' (Walker, 2010), 'team flow' (van den Hout, 2018) or 'networked flow' (Gaggioli et al., 2013). This is when the state of flow is shared by a group of individuals, such as a sports team, or a working group. Group flow has been found to bring enhanced creative production and improved performance (Sawyer, 2007; van den Hout, 2018). Although a strong association has been found between flow and music on an individual basis, there has been little focus on group flow in the context of music (Chirico et al., 2015; Hart \& Di Blasi, Z., 2015). In this article, I will examine the nature of the group flow of Black Sabbath and Joy Division, and how it facilitated their high degree of environmental expression.

Separated by around 10 years, Black Sabbath and Joy Division were loosely allied to musical trends of their time. Black Sabbath emerged from the blues rock genre of the late 1960s, whereas Joy Division emerged from the post-punk movement of the late 1970s. Nevertheless, both bands were highly original, and have proved to be remarkably influential. I will argue that the power and influence of both bands stems from the two sources I have mentioned above: that is, their high degree of group flow, and their ability to channel their shared environmental experiences. The bands' group flow enabled them to channel music spontaneously and instinctively, without conscious deliberation, facilitating a level of creativity and performance that transcended them as individuals.

In other words, the music of Joy Division and Black Sabbath (including their lyrics) can be seen as a 'soundscape' depicting broadly similar environments. As Bernard Sumner of Joy Division wrote 34 years after the band's demise, 'Joy Division sounded like Manchester: cold, sparse and at times, bleak' (Sumner, 2014: 7). Or as McIver has noted of Black Sabbath, 'Thanks to the group's terrible socioeconomic background, glum worldview, limited skills and dearth of opportunities, Black Sabbath's route was always likely to be into the darkness' (2013: 35).

\section{Channeling the Sounds of Industry}

On one level, Black Sabbath and Joy Division may not seem to have much in common. Indeed, it is probably not so easy to find music fans who admire both of them, since the bands are usually seen as belonging to different genres. Blues rock and post-punk are not particularly amenable genres - in fact, one of the core principles of both punk post-punk was to eschew hallmarks of blues rock (and heavy rock or progressive rock) such as overt musical virtuosity, extended soloing, long songs, and escapist non-socially relevant topics. Punk and post-punk rejected these in favour of concision, lack of pretension, simple musical technique and topical socially-conscious lyrics (Savage, 2005). However, it could be argued that, whilst still being affiliated with their genres to some degree, Black Sabbath and Joy Division moved beyond them, into a shared musical and cultural space. 
The most obvious similarity between the two bands is their darkness and heaviness in sound and subject matter. (In fact, both bands possessed a strong congruity between form and content which gives their music a strong sense of cohesion). The darkness and heaviness in sound are related to a low end, bass heavy overall sound, with an avoidance of major keys and a lack of the circularity and resolution of conventional song structures. The darkness and heaviness of lyrical content relates to a preoccupation with bleak and nihilistic themes, including personal alienation and mental disorder and (particularly in the case of Black Sabbath) social issues such as war and drug addiction. These factors will be examined in detail later in this paper.

The common darkness and heaviness of the bands can be seen as a direct influence (and depiction) of the similar environments which their members emerged from. The members of Black Sabbath grew up in the bleak, war-ravaged environment of Aston, an industrial inner-city area of Birmingham, in the heart of the Black Country. Their immediate environment consisted of factories, terraced houses, chimneys spewing smoke into the air and uncleared bomb sites from the Second World War (Osborne, 2010).

The background of Joy Division was similar. The two main musical forces of Joy Division bass player Peter Hook and guitarist Bernard Sumner - grew up in the deprived area of Salford, near Manchester, in the 1960s and 1970s. As Sumner has described his childhood environment, 'within a few minutes' walk, there was a potted version of the entire, industrialized north-west: an iron works, copper works, cloth-finishing works, paint factory, chemical works, cotton mill, saw mill and brass foundry' (2014: 10). Although there was a healthy sense of community spirit in 1960s Salford - fostered by the rows of terraced houses that opened directly on to the street - there was a continual threat of violence, and a strong emphasis on 'toughness' in character, expressing itself in a cold, emotionless masculinity (Hook, 2012; Sumner, 2014). Joy Division's singer, Ian Curtis, was also from a working-class background, born in Manchester but raised in Macclesfield, a small town about 20 miles south of Manchester. Drummer Stephen Morris was also from Macclesfield, the only member of Joy Division from a more affluent, middle class background.

The connection between both bands' music and the urban industrial environment has been made before. For example, Cope (2010) has linked the anger, aggression and angular nature of Black Sabbath's music to their bleak industrial environment. As he writes, 'one cannot dismiss simply as coincidence that the dark, angry and serious forms of music evident in the early work of Black Sabbath seems to correlate to the darkness, depression, boring school and dead end, working class factory life of the industrial Midlands' (2010: 27). In the case of Joy Division, music critics recognised the 'psychogeographic' aspect of their music right from the beginning. As John Savage wrote in a review of Unknown Pleasures shortly after the album's release in 1979, 'Joy Division's spatial, circular themes and Martin Hannett's shiny, waking-dream production gloss are one perfect 
reflection of Manchester's dark spaces and empty places: endless sodium lights and hidden semis seen from a speeding car, vacant industrial sites' (Savage, 1979). Or as McCready has put it, 'Unknown Pleasures would have seemed a perfect psychogeographical soundtrack. Ian Curtis intones bleakly of walking through the city limits, of drinking and shadowy passers-by, of rust and decay and sinister cars waiting outside' (2002: 96-97).

The sound that both bands created was redolent of this barren industrial background. As Nevarez has put it, 'Perhaps more than any other Mancunian band, Joy Division are claimed to sound like Manchester, at least the Manchester of a certain era' (2013: 56). Clearly, most music carries some environmental influence, and there is a strong relationship between city life and rock music in general (see Lashua, Spracklen \& Wagg, 2014). As Gillet has put it, '... rock and roll was perhaps the first form of popular culture to celebrate without reservation the characteristics of city life that had been amongst the most criticized. In rock and roll, the strident repetitive sounds of city life were, in effect, reproduced as melody and rhythm' (1994: viii). In this context, one could argue that Black Sabbath and Joy Division simply expressed the relationship between city life and rock music especially powerfully and directly - and also that, in both cases, they depicted a particular type of degraded and bleak urban environment.

In the following section I will highlight a number of more specific ways in which both Black Sabbath and Joy Division channeled their industrial environment. These are (1) their low end, bass heavy overall sound; (2) more specifically, the guitar sound of both bands; (3) the austerity of their sound; (4) the repetitive and continuous quality of their music; (5) the rigid, mathematical structure of songs and performances; and (6) lyrical content. I will examine each of these aspects in turn, before moving on to examine the unusual level of group flow that allowed the bands to channel their environmental influences so directly and powerfully.

\section{Overall Sound}

The primal, bass-heavy, riff-based sound of both bands is redolent of the factory environment. Sonically, industrial environments are full of bass frequencies, including the rumble and thunder of machines, conveyor belts and trains and cars. Of course, high frequencies may also be present in industrial environments, such as screeching of metal or the hammering of metal, but these tend to be more incidental and sporadic than the bass frequencies, which form a constant background noise. There is also a relative absence of natural higher range frequencies, such as bird song and the sound of wind blowing through trees or bushes. The lack of melodic brightness and high range in both bands' sounds helps to convey the actual darkness of the industrial environment, with smoke and tall buildings (and the cloudy skies of both Manchester and Birmingham) blocking out sunlight. 
Until the advent of thrash metal, it was unusual to find bands who contained so much low end and so little mid or high end in their music (Herbst, 2017). In Sabbath's case, riffs were mainly played with power chords (also known as fifth chords, since they consist simply of a root and fifth note) on the bottom two strings of a (usually) down-tuned guitar. In Joy Division's case, riffs were played on a mildly distorted bass guitar.

In a discussion of the use of distorted electric guitar in metal music, Herbst (2017) notes that the quality of heaviness in metal music largely stems from use of power chords and distortion, which extends the guitar signal both to higher and lower frequencies. Although power chords were not frequently used by Joy Division, Hook's mildly distorted bass riffs accompanied with the further distortion of Bernard Sumner's guitar, and the frequent use of tom toms by drummer Stephen Morris created a similar sense of heaviness (e.g. 'Dead Souls' or 'Atrocity Exhibition').

Both bands also avoid the brightness of major third notes. The absence of third notes is a primary characteristic of power chords. Third notes - whether minor or major - offer a sense of completeness and resolution, and the lack of them confers a sense of both primal simplicity and slight ambiguity and even unease. Seventh notes and chords are also rarely - if ever - used by both bands. Since seventh notes are associated with blues and folk, one would not expect to find them in the post-punk music of Joy Division, but they were commonly used by Black Sabbath's blues rock contemporaries, such as Cream and Led Zeppelin. This is further evidence of Sabbath's originality, and their departure from the conventions of blues rock. The absence of third and sevenths notes conveys an elemental, stripped down quality, creating an overall sense of intensity and power.

This points to another feature of both bands' overall sound: their avoidance of the melodic conventions of blues, and blues rock. Again, this is not surprising in Joy Division's case, but more so in relation to Sabbath. Although Sabbath's eponymous first album occasionally flirts with blues rock conventions (using 12 bar structures and blue scales in 'The Wizard' and 'Evil Woman', for instance) from the Paranoid (1970) album onwards, these were largely abandoned. Cope has suggested that, while Tony Iommi occasionally used the blues scale in riffs, 'he made no significant use of the blues scale in his soloing' (2010: 63). This is in complete contrast to Eric Clapton and Jimmy Page (of Cream and Led Zeppelin, respectively) whose solos and riffs were largely blues based (particularly in Clapton's case). Cope has characterized Sabbath's 'melodic syntax' as consisting of 'pure pentatonic and modal stylisations' (ibid.) Sabbath made use of unusual features such as flattened second notes (for example, when an $\mathrm{E}$ is followed by an F), and tritones. The tritone (also called a diminished fifth) was once known as the 'devil's interval' because of its sinister dissonance (McIver, 2013). It was used prevalently in Sabbath songs such as 'Black Sabbath' and 'Symptom of the Universe.' 
The darkness and heaviness of both Black Sabbath and Joy Division also stems from drumming styles. The drum patterns to most of their songs are unusual in that they frequently (most frequently in the case of Joy Division) avoid the brightness and stability of traditional regular, 4/4 hi-hat and snare patterns. One example from Black Sabbath is the song 'Black Sabbath,' which utilises rumbling tom toms throughout the verses and irregular snare-based rhythms elsewhere. Both drummers (Stephen Morris of Joy Division in particular) used tom-toms to an unusual degree. Joy Division songs such as 'Atmosphere' and 'Dead Souls' utilise 16 notes throughout on the tom toms, with no use of hi-hat at all. Therefore, percussively both bands are unusually oriented around the bass range.

Another way in which Sabbath's drummer Bill Ward was unusual is the extent to which, rather than 'laying down' a rhythm for the rest of the band to play on top of, he closely followed Tony Iommi's riffs. In a song such as 'Iron Man', for instance, the drum pattern exactly echoes the rhythm of the riff. (As in many Sabbath songs, Ozzy Osbourne's vocal melody simply follows the riff as well, resulting in a monolithic, primal sound.) Sabbath drummer Bill Ward has specifically linked his drumming style to the percussive industrial sounds he would hear in his bedroom in Birmingham. He has described how, lying awake at night listening to the pulsating rhythms of machinery, he would tap out fills and rolls on his headboard (Cope, 2010). McIver also notes that Ward often 'dragged' the beat for 'a microsecond or two for a dark, doomy feel that gave the songs enormous power' (2013: 39). According to Ward, this created a sense of 'grogginess and awkwardness in the music' (ibid.).

\section{Guitar Sounds}

The industrial influence of Joy Division and Black Sabbath is perhaps most obvious in the guitar sounds of both bands. Tony Iommi's and Bernard Sumner's sounds are similar: a bass-heavy, metallic, distorted sound, mainly utilising the low end notes of the guitar (except for solos) and avoiding full chords. Significantly, both used Gibson SGs, although Sumner used a Vox amplifier (with distortion pedal) while Iommi used Marshalls (and later Laneys).

Working in a factory at the age of 17 , Tony Iommi had an accident in which he lost the tips of the two middle fingers of his right hand (his fretting hand, since he played guitar left-handed). He feared that his career as a guitarist was over, before his foreman at the factory lent him an LP by the Belgian guitarist Django Reinhardt, who fretted the guitar with only two fingers, after losing the others in a fire. Encouraged by this, Iommi made plastic tips for his fingers, and found that he was still able to play, although he had to make significant adjustments. He began to use thinner banjo strings rather than regular guitar strings, to ease the pressure on his fingers. In addition, since he 
found it hard to play full chords, he began to mainly play two-finger fifth chords (with his two undamaged fingers), moving up and down the 6th and 5th strings (Iommi, 2012; Pepper, 2013).

Thus, Iommi's use of power chords - which became a defining feature of metal music (Herbst, 2017) - was accidental. As Iommi himself put it, 'I had to work really hard to get around it. I had to play more simply...I had to think of ways of playing that were effective but still possible for me' (in McIver, 2006: 38). As Pepper points out, these limitations actually equated to creative freedom and led to a 'monumental creative achievement (the invention of metal)' (Pepper, 2013: 59). (2)

Perhaps the most influential aspect of Tony Iommi's guitar sound was his practice of downtuning. Again, this was a measure to reduce the pressure on his fingers. At the start of their career, Sabbath tuned down a semitone for live performances, but recorded their first two albums in standard tuning. However, by Master of Reality (1971), Iommi had begun to downtune his guitar three semitones, so that E string became C\#. This continued (with some variation, such as downtuning just two semitones for some songs) until later albums such as Technical Ecstasy (1976) and Never Say Die (1978), when Iommi reverted to standard tuning (Iommi, 2012). Combined with his thinner strings and use of power chords, this guitar sound became the primary component of the bass heavy. dark, doomy sound which was (at the time) unique to Black Sabbath.

Iommi's guitar sound was extremely influential - although curiously this influence did not manifest itself noticeably until the 1980s and 1990s, with the development of death and doom metal. Many bands adopted the practice of down-tuning, as a way of darkening sound and gaining power (Mynett 2013). Typically, death metal and grindcore bands (such as Cannibal Corpse and Napalm Death) tuned down between one and three semitones. More extremely, Carcass tuned down 5 semitones to B. In more recent years, the trend has continued, with some bands tuning down even further (Herbst, 2017). In 1999 Berger (1999: 58) noted that the history of metal was characterised 'as a progressive quest for ever-heavier music' and this process has continued ever since.

In the case of Joy Division, Bernard Sumner's style was very different from Iommi's in that he seldom played along with the riffs of bass player Peter Hook, preferring to embellish them with short melodic phrases, often in the spaces between verses. Despite the similarity of sound (and choice of instrumentation) to my knowledge, Bernard Sumner has never referred to the influence of Tony Iommi. It is perhaps the case that the common elements of their sound were not the result of direct influence, but of the indirect influence of their shared industrial environment. 
Another common way in which the bands expressed their industrial environment is through sparseness of instrumentation and sparseness of sound. Both bands stuck largely to a simple arrangement of guitar, bass, drums and vocals, with occasional overdubs for guitar solos (and occasionally basic keyboard accompaniment). Some Joy Division songs (particularly on their first album Unknown Pleasures [1979]) consist mainly of bass and drums, overlaid with fragments of guitar sounds or melodies, sound effects and minimal vocal lines. This sparseness conveys spaciousness, but whereas the spacious minimalism of (say) Miles Davis's Kind of Blue or Brian Eno's ambient work creates a sense of rich and relaxing openness, Joy Division's spacious minimalism creates a sense of threat and unease. One could an analogy between a relaxing spaciousness of a natural landscape (which applies to Kind of Blue or Eno's work) and the threatening emptiness of a derelict wasteland in an urban landscape (which applies both to Black Sabbath and Joy Division). It appears that the sparseness and spaciousness of sound amplify the qualities of the music which inhabits the empty sonic space. For example, the dark and angular music of Joy Division creates a sense of unease that reverberates through the open sonic space; while the harmony of Miles Davis or Eno generates a positive atmosphere that fills the space

Another similarity - and source of austerity - are the vocals. In both bands, vocals are almost always performed solo, without backing vocals or harmonies. In Joy Division's case, Ian Curtis's vocal lines are short, sung in a staccato style, without vibrato. The stiff, staccato style conveys a sense of distance and emotionlessness. Ozzy Osbourne sang fairly minimally throughout many Black Sabbath songs, many of which contain extended instrumental passages. Although his low tenor voice is clearly very different to Ian Curtis's, Osbourne also sang largely without vibrato. This is one of the many factors which distinguished Sabbath from their blues rock or heavy contemporaries, since vibrato was a key element of the vocals of blues-rock singers. For example, Osbourne's singing of the lines of the verses of 'War Pigs' (e.g. 'Generals gathered in their masses') contains a single note which is held for a whole bar without vibrato. Compare this to Ian Gillan's singing in Deep Purple's 'Child in Time,' when high notes are held for one bar or longer with extensive vibrato.

The sparseness of instrumentation and general austerity of sound can be seen as an expression of both bands' austere and barren industrial environment. The lack of harmony and melodic richness helps to convey the bleakness and deprivation of cities such as Birmingham and Manchester in the 1960s and 1970s.

Repetition and Continuity 
Machines are characterised by repetition and continuity, which are also features of the music of Black Sabbath and Joy Division. Neither band played songs in any traditional sense - that is, they did not utilise a standard pop structure of verses and choruses (or hooks) with middle eights or bridges. There are very few songs with conventional structures in either band's catalogue. Joy Division's 'Love will Tear us Apart' - not coincidentally, their only significant chart success as a single - is an exception. It is not easy to think of Black Sabbath songs with a chorus - 'Changes', from Black Sabbath Volume 4 (1972) springs to mind, which was later a chart success in an asinine duet between Ozzy Osbourne and his daughter. As Cope (2010) points out, Sabbath's songs are generally multi-sectional and episodic, lacking the circularity of conventional pop or blues songs. Although Sabbath had roots in blues rock, it is notable that (especially after their first album) they eschewed blues conventions such as a repeating twelve bar structure. Sabbath songs often contain a 'main body,' based on a primary riff, followed a series of segments based on other riffs, some of which seem to be only loosely connected to the main riff. Sometimes the different sections are in a different rhythm and even in a different key to the main section of the song. In many cases, the band does not return to the main riff. This description fits to many of the band's most revered songs, including 'Wheels of Confusion', 'Killing yourself to Live,' 'Sabbath Bloody Sabbath' and 'Symptom of the Universe.' Like Joy Division, Black Sabbath only had one 'hit single', 'Paranoid,' which, unusually for a hit single, does not feature a chorus. Another single, 'Never Say Die', was a minor hit in 1978, and did feature something approximating to a chorus.

Because of this departure from traditional song structure, there is a sense in which both band's songs do not resolve, or even end., which lends a strange sense of incompleteness to the songs. Less complex than Sabbath songs, Joy Division songs usually contain one single riff, locked together with a drum rhythm and repeated without variation, in a metronomic and mechanical way. Guitar phrases overlay and intersperse the repeated riff, with a vocal melody on top. Songs such as 'Heart and Soul' and 'Colony' are based on two bar bass guitar riffs which repeat for the whole duration of the song, and which one could imagine repeating indefinitely, like the endless churning machines of a factory. Live recordings reveal Joy Division songs grinding to a close rather than finishing, almost like a machine being turned off and slowly petering out. Many songs end with each instrument dropping out in turn after the final verse - first the guitar, then the bass, and finally the drums.

In other words, both bands' songs do not resolve in the same way the highly structured songs of the Beatles or the Kinks - or even tightly structured progressive rock bands such as Yes or Genesis. This is another source of the unease and austerity of both bands, since a resolution usually brings a sense of order and cohesion to a song. 


\section{Rigidity}

However, this is not to say that the bands' songs are unstructured. In fact, their songs are rigidly structured, but according to different criteria. This is a further way in which they express their shared urban-industrial environment. In relation to Joy Division, there is a regular, mathematical quality to their music which is clearly redolent of industry. Drummer Stephen Morris was heavily influenced by 'Krautrock' bands such as Neu! and Kraftwerk and their motoric, repetitive rhythms (Morris, 2019). On top of Morris's motoric rhythms (often providing 16 beats to the bar hi-hat or tom tom patterns), Peter Hook's bass riffs are almost invariably eight beats to the bar throughout the whole song, while Ian Curtis's vocal lines are also extremely regular, with the same syllabic patterns rigidly repeated (and also, as mentioned before, sung without vibrato).

One of the most striking differences between Black Sabbath and their heavy rock contemporaries was their strict adherence to song structures in live performances. In the late 1960s and early to mid 1970s, rock music was characterised by jamming. Songs were extended and extemporized, and rarely played the same way twice. As in jazz, the basic structure of the song served as a springboard for variations and improvisations, often with extended guitar and keyboard solos (and sometimes drum solos too). The songs of Black Sabbath's close contemporaries Led Zeppelin and Deep Purple could extend for more than 20 minutes. The bands' live albums, The Song Remains the Same (1976) and Made in Japan (1972) respectively, contained 7 and 9 songs over four sides of vinyl each. But Black Sabbath rarely (if ever) jammed. Live recordings show them adhering very rigidly to the original structures of songs as recorded.

This was specifically true of Ozzy Osbourne's style of singing too, and another way in which his style differed from his contemporaries. Whereas rock singers typically improvise and vary melodies - Robert Plant in his Led Zeppelin days is a good example - Ozzy Osbourne tended to stick rigidly to the pre-established melody lines, in a way that is more typical of pop and new wave (or post punk) songs than rock. The rigid structure of both band's songs and performances arguable relates to the mechanism of the industrial environment, which is characterised by mathematical regularity, monotony and a lack of spontaneity.

\section{Lyrical Concerns}

Finally, the shared bleak industrial environment of the two bands was also expressed through their lyrics. The lyrics of Joy Division tend to be subjective and personal, often alluding to a sense of alienation and mental disorder, the extent of which was shockingly revealed with the suicide of singer and lyric writer Ian Curtis in 1980. At the same time, Joy Division's songs depict a 
psychogeography of barren urban landscapes, made up of motorways, concrete and streetlights. The bleak urban landscape mirrors the bleak mental landscape which is the primary theme of the lyrics.

The lyrics of Black Sabbath tend to be more outward looking and socially oriented, with songs about war (such as 'War Pigs' and 'Hand of Doom'), drugs (such as 'Sweet Leaf, 'Hand of Doom' again and 'Snowblind') and religion (e.g. 'After Forever') as well as songs with satanic themes (such as 'N.I.B.' and the song 'Black Sabbath'). Barnett summarises Sabbath's lyrical themes as 'such as war, death, social chaos, the supernatural and the conflict between good and evil' (2017: 82).

Nevertheless, both bands share a similar bleak, even nihilistic outlook. There are many Sabbath songs that deal with alienation and mental disorder, such as 'Paranoid', 'Wheels of Confusion' and 'Am I Going Insane?' The lyrics of such songs occupy a very similar psychological space to Joy Division, dealing with fears of encroaching mental dislocation, a fear of losing control over one's mind, disillusionment (with the death of naive childhood hopes and dreams), and feelings of alienation. Clearly, death and doom metal bands were influenced by Black Sabbath in terms of lyrics and subject matter (Yuzuz, 2017).

In fact, there are a number of Sabbath lyrics which are almost interchangeable with Joy Division lyrics. For example, here is a sample verse from Sabbath's 'Wheels of Confusion': 'Lost in the wheels of confusion/Running through valleys of tears/Eyes full of angry delusion/Hiding in everyday fears' (Black Sabbath, 1972). This is also true of some of the lyrics of 'Paranoid': 'I need someone to show me the things in life that I can't find...Happiness I cannot feel and love to me is so unreal' (Black Sabbath, 1970). There are many Joy Division lyrics which resonate with these lines, conveying a similar sense of disillusion and desperation - for example, 'Now that I've realised how it's all gone wrong/Gotta find some therapy, this treatment takes too long' (from 'Twenty Four Hours,' Joy Division, 1980) or 'Can I go on with this train of events?/Disturbing and purging my mind/Back out of my duties, when all's said and done/I know that I'll lose every time' (from 'Passover,' Joy Division, 1980). Barnett has noted that 'the plight of the tragic hero in "Paranoid" is synonymous with the universal theme of mental affliction and suffering permeating Greek tragedy' (2017: 91). This is true of many Joy Division songs too, such as 'Passover' and 'Twenty Four Hours,' in which the protagonist describes feeling alienated and overwhelmed by a hostile world, and yearning for healing and escape.

This bleakness of outlook was part of the cultural landscape of the post-punk era, shared by many of Joy Division's contemporaries, such as PIL and Gang of Four. In the case of Black Sabbath, this outlook was more idiosyncratic, since most of their late 60s contemporaries were still singing optimistically about love and peace. Such naive positivity seemed incongruous in the bleak landscape of Aston in the 1960s. Froese has suggested that the 'sinister sounds' of Black Sabbath 
were a rebellious response to the 'the liberal 1960s middle-class counter-culture' (2013: 21). This was true of their lyrics too, which as Barnett has suggested, 'ran counter to the more uplifting and optimistic lyrical themes inherent in many songs synonymous with, the hippie era' (2017: 82). This again highlights the organic and authentic nature of Sabbath's music. At the same time, as I mentioned previously, this meant that, for both Joy Division and Sabbath, music and lyrics cohered closely, to produce a holistic, well-integrated and artistically satisfying body of work.

One of the most striking aspect of Black Sabbath's lyrics is the lack of what Walser (1993) has referred to as 'gender anxieties' - that is, a preoccupation with heterosexual romantic and erotic relations, including themes of romance, unrequited, heartbreak, misogyny, jealousy and sexual conquest. This is another factor that differentiated Sabbath from their blues rock and heavy rock contemporaries. In fact, as Cope (2010) points out, these are the themes which drive most blues, rock and roll and pop songs in general. However, these themes were largely absent from Sabbath's songs, which was another facet of their originality. (3)

\section{Group Flow}

Now I will turn to the second main aspect of this paper: the group flow that enabled both bands to channel their environmental experiences so directly and powerfully. As mentioned at the beginning of this article, flow refers to a state of intense absorption in a challenging or stimulating activity (Cskiszentmihalyi, 1990). Group flow is similar, but with the added quality of the synergy and intersubjective connection of two or more individuals. In group flow, a group of individuals becomes more than the sum of their parts, and 'tunes in' to one another in a subtle way. In doing so, they become capable of remarkable creative (or athletic, in the case of sports teams) feats.

As one of the leading researchers into group flow, Keith Sawyer, has defined it, group flow is a 'a collective state that occurs when a group is performing at the peak of its abilities' (Sawyer, 2003: 167). Sawyer has even suggested that group flow can exist when the members of a group are not individually in a state of flow:

Group flow is not the same thing as the psychological state of flow. It depends on interaction among performers and it emerges from this process. The group can be in flow even when the members are not; or the group might not be in flow even when the members are. The study of group flow thus requires a fundamentally social psychology and must proceed by examining the interactional dynamics among members during performance (2006: 159) 
Group flow emerges from a number of interacting factors, mostly depending on the relationships between members of a group. Psychologists have stressed the importance of factors such as team interaction (Russel, 2001), partner unity (Jackson, 1995) and balanced decentralization and synchronization (Armstrong (2008). According to Quinn. group flow emerges when a group of individuals move 'together toward shared or complementary goals, adjusting in real time to each other's expectations, needs, and contributions' (2005: 637).

Similarly, Sawyer (2007) has highlighted a number of conditions which must be met in order for group flow to emerge, including a common goal, spontaneous creativity (without conscious deliberation), the blending of egos, equal participation, communication, familiarity and a sense of forward movement. If such conditions are met, what Sawyer (2007) describes as a 'genius group' may emerge.

These are criteria that both Black Sabbath and Joy Division adhere closely to. It is significant that the members of both bands had strong personal friendships (at least in their initial most creative stages). They were not bands made up of hired hands or session musicians, but friends from the same (or at least a similar) environment, who had developed their music together from the beginning, forming a close personal and musical bond. They were of similar ages, from similar socio-economic backgrounds, with a similar limited degree of musical experience and lack of professional status. These factors must have fostered factors such as the blending of egos, equal participation, communication and familiarity (Sawyer, 2007).

It is significant that both bands created music in a highly collaborative, organic way. Unlike most bands, there was not one or two single creative forces, who pre-wrote most of the songs, which were then arranged and rehearsed by the whole group for performance and recording. The collaborative nature of both bands' creativity is reflected in the fact that - unusually - songwriting credits were shared equally amongst all members.

In Black Sabbath, the raw material of songs was normally the guitar riffs of Tony Iommi, which were then collaboratively honed into finished pieces. Ozzy Osbourne would find vocal 'top lines' - or melodies - that fitted with the riffs (Wall, 2014). Although Ozzy sometimes provided basic lyric phrases (and occasionally whole songs), lyrics were mainly written by bass player Geezer Butler (Osborne, 2010; Wall, 2014).

In Joy Division, songs were collaboratively honed in a similar way. Songs were built up during rehearsals, from the 'raw material' of either the bass riffs or tom-tom based drum patterns. The three musicians would collectively jam, with singer Ian Curtis leafing through a notebook of lyrical ideas, and trying out vocal 'top lines' over the music (Hook, 2012; Sumner, 2014). In the cases of both bands, this collaborative creative process would have lent itself to the development of 
social flow, fostering the qualities of interaction (Russel, 2001), partner unity (Jackson, 1995) and balanced decentralization (Armstrong, 2008).

\section{Output}

Both bands' high level of social flow is also indicated by the unconscious nature of their creativity, involving a lack of conscious deliberation. This is a theme that continually crops up in the memoirs of the surviving members of Joy Division. As Stephen Morris has recalled in relation to Joy Division's music, 'We never talked about it or thought about it. It just worked' (2019: 171). Or again: 'One thing we never did was sit down and talk about what the hell we were doing' (in Male, 2020: 75). Similarly, Ozzy Osbourne noted in relation to the spontaneous creation of 'Paranoid', 'That's the way it always is with the best songs: they come out of nowhere, when you're not even trying' (Osbourne, 2010: 111).

In retrospect, Peter Hook reflected that Joy Division's intense and spontaneous creativity was partly due to a lack of knowledge of musical conventions and a lack of conscious deliberation:

Musicians stop writing great music when they learn about the formal process of making music...The more proficient you become at writing music they less risks you take because you become aware of all the rules and theories that may be the proper way to do things but end up constricting you, throttling all the creativity out of what you've got. No more risk-taking. Back then we didn't know anything about rules or theory (Hook, 2012: 141).

Under conditions of social flow, the spontaneous and collaborative creative process often leads to a high level of effectiveness and performance, with a high level of productivity (Thackman and Wageman, 2005; Sawyer, 2007). The prolific output of both Black Sabbath and Joy Division offers evidence of this. In a professional recording career lasting less than two years, Joy Division recorded over 40 songs. In a period of two and a half years - February 1970 to September 1972 Black Sabbath released four full length albums, at a time when they were touring almost constantly.

From the members of both groups' descriptions, songs almost seemed to be coming through them rather than from them, as if the band members were serving as channels for the music. In a 2013 interview with Mojo magazine, Geezer Butler said, 'The first four albums just came from nowhere. We were on the road forever, and in two years we had done four albums and God knows how many tours' (Alexander, 2013: 75). Similarly, Joy Division bassist Peter Hook has described how their songs 'just flowed like rain...We couldn't stop writing them' (2012: 140). Drummer Stephen Morris has recalled that when not touring Joy Division would usually write a new song 
very week, during two short rehearsal sessions. Typically, a new song would be worked up during a three hour rehearsal on Wednesday evening, and completed the following Sunday, during a two hour session (Morris, 2019).

Joy Division's most famous song 'Love Will Tear us Apart' was written in three hours (Hook, 2012), while Black Sabbath's 'Paranoid' was written in twenty minutes, after the band were asked to 'jam something' at the end of a studio session, as they were still a few minutes' short of a full length album (Osbourne, 2010; Iommi, 2012). Similarly, both bands' pivotal albums were recorded very quickly. Sabbath's eponymous first album was recorded in one day, while Joy Division's first album Unknown Pleasures was recorded and mixed over just three weekends. Although it had been common for bands to record albums quickly during the early to mid-sixties, by the late 60 s and early 70 s, it was becoming increasingly common for bands to spend long periods in the studio. For a point of comparison, another 1970 album, Déjà vu, by Crosby, Stills, Nash and Young, is reputed to have required 800 hours of studio time (Crosby, 1988).

A related theme here is both bands' lack of intellectual understanding of their own music, which provides further evidence of the spontaneous or unconscious creativity that emerges in group flow. As McIver has concluded after several interviews with members of Black Sabbath, 'The truth is, none of them really know how they made their music sounds so evil...ask any of them abstract questions about how and why Sabbath's songs possessed nebulous qualities such as heaviness, scariness, and so on, and you'll get nowhere' (2013: 34). McIver concludes that Sabbath created 'their music from a position where they didn't understand the significance of what they were doing' (2013: 34).

In the case of Joy Division, there was a marked disconnect between the band members' outward personalities and behavior and the music they created. As individuals, Joy Division were at least superficially - completely unlike the serious and dark image projected by their music. They were, as Peter Hook describes it, 'young lads, fucking about, living the rock and roll dream, playing jokes, having a laugh, reading dirty magazines' (in Morley, 2016: 124). Only singer Ian Curtis displayed an overtly serious and intellectual aspect to his personality, although he often behaved in the same 'laddish' way as the other members of the band (ibid.). This disconnect again illustrates the quasi-channeled nature of Joy Division's music, as if the music was coming through rather than from them.

The Loss of Group Flow

As mentioned previously, social flow is a subtle state depending on a variety of different factors. As such, it is easy to lose. In Black Sabbath's case, the state of group flow appears to have dissipated in 
the mid-1970 due to legal problems, substance abuse and fractious relationships, leading to a loss of conditions such as the blending of egos, equal participation, communication, familiarity and a sense of forward movement (Sawyer, 2007). This was reflected in the band's declining creativity and productivity. In particular, later albums such as Technical Ecstasy (1976) and Never Say Die! (1978) had a difficult gestation and were viewed as highly unsatisfactory by band members (Osborne, 2010; Iommi, 2012).

After the demise of Black Sabbath, singer Ozzy Osbourne initiated a very successful solo career, with significantly higher record sales than Sabbath themselves. However, Osbourne's solo music was largely a pastiche of Black Sabbath, full of ersatz heaviness and darkness, and exaggerating Sabbath's satanic or 'black magic' themes to an almost comic degree. The remaining members of Sabbath managed to sustain their creativity for two critically respected albums with Ronnie James Dio, but after the departure of drummer Bill Ward and bassist Geezer Butler, the band's main creative force, Tony Iommi, struggled to replicate Sabbath's previous alchemy with a succession of different vocalists and musicians (Wall, 2014). In 2013, three-quarters of the original band (all except drummer Bill Ward) reconvened to record the critically acclaimed album 13, which suggested that the group flow they had established earlier could be reestablished.

In Joy Division's case, the death of Ian Curtis in 1980 meant that the band ended at the peak of their creativity and productivity - that is, in the midst of a sustained state of group flow. After the death of singer Ian Curtis, the three surviving members of Joy Division renamed themselves New Order and pursued a very different musical approach. In some ways their music was a logical extension of the mathematical and rigid elements of Joy Division, with New Order's extensive use of sequences and drum machines. However, overall, the music was much lighter, moving away from the bass-heavy sound of Joy Division towards treble frequencies and major keys. Lyrical themes of alienation and mental illness were abandoned, as was Bernard Sumner's metallic guitar sound. This was a conscious attempt at reinvention, and led to some groundbreaking music, showing that the three remaining members were able to generate a different form of group flow. However, New Order have arguably never managed to recapture the same spontaneous, quasichanneled creativity of Joy Division, perhaps because of the conscious deliberation that their reinvention required.

\section{Conclusion}

Group flow has been studied extensively in the work environment (e.g. Lucas, 2018) and the relationship between flow and music has been studied intensively on an individual basis (see Croom, 2012) but as yet, there is little research on group flow in a musical context. As Chirico et al. 
note, 'another future challenge for research in this field could be a group perspective of analysis toward flow in music. Indeed, in all the selected studies the relationship between music and flow has been investigated mainly at the individual level' (2015). In my view, it would be very fruitful to investigate this in all areas of popular music, including all forms of metal music. It would be interesting to find out whether different forms of music (for example, jazz) are more strongly associated with social flow, or at least different levels or different types of social flow. It would also be interesting to examine levels and types of social flow in successful bands, focusing on the different factors which gave rise to it, and how it was maintained or lost. How common is what Sawyer (2007) calls a 'genius group' in popular music? Can a genius group transcend the talents and abilities of individuals, so that the group becomes much more than the sum of its parts?

One could argue that any successful band has to develop some degree of group flow. Perhaps one could make a distinction between two types of groups, relating to how group flow expresses itself. The first is groups whose music stems from one or two (or perhaps more) individual creative forces, usually songwriters (and perhaps also arrangers and producers) to whom other members of the group are subservient. The Beatles, Led Zeppelin, The Smiths or the Sisters of Mercy are good examples. Such groups might well possess a degree of group flow, but this may manifest itself primarily in the context of performance. As musicians, the members may develop a deep understanding which facilitates improvisation, or simply ensure that they play the band's songs fluently and proficiently. Led Zeppelin and Deep Purple are a perhaps good examples of bands whose members had (at their peak) a group flow which manifested itself primarily in performance, which enabled them to improvise with great facility.

The second type of group are collectives in whom creativity is not so individually concentrated, and songs are created co-operatively by the whole band rather than by individuals. In other words, in these bands group flow manifests itself in the compositional stage, rather than just in performance. This type of group is quite rare - in pop and rock music, it is standard practice for songs to be pre-written by one or two main creative forces. Arguably, this second type of group requires a more intense degree of group flow than the first type.

Black Sabbath and Joy Division were examples of the second type of the group. This enabled them to become pure conduits of environmental influences and unconscious psychological forces. The music of both bands is so powerful because it carries such a strong imprint of the environment they emerged from. It was a spontaneous unconscious outpouring of a particular cultural experience of mid-to-late 20th century Britain. The darkness of their environment became the darkness of their music, in a very pure and primal way, and with a powerful spontaneous creativity which - paradoxically - gave the music an uplifting transcendent quality. 
Notes

(1) The heaviness and darkness of both band's music can be polarising. As Yavuz (2017) has described in relation to death/doom metal (two genres on which Sabbath have had a significant influence), heaviness and darkness - and a preoccupation with themes of isolation, alienation and depression can have a comforting and consoling effect on some listeners ('delightfully depressing' in Yavuz's term), while others may find it oppressive. Barnett (2017) has suggested that Black Sabbath's bleak lyrics - depicting extremes of human suffering - have a powerful cathartic effect which is similar to Greek tragedy. Such potentially positive effects of listening to metal music were also identified by Sharman \& Dingle, 2015, who found that even extreme metal music did not increase aggression in listeners but, on the contrary, served as a positive means of processing anger).

(2) There is a similar case of creative innovation through enforced limitations in another guitarist, Joni Mitchell, who lacked strength in her fingers after contracting polio as a child. Finding normal full chords difficult to hold down on an acoustic guitar, Mitchell developed a playing style based entirely on different open tunings, so that she could hold down the root chord of a song without using her left hand at all. From 1968 to1998, Joni Mitchell did not record any songs in standard tuning, and has used 51 different tunings in her songs (Williamson, 2005).

(3) Cope (2010) has discussed the originality of Sabbath's music at length, contrasting them with Led Zeppelin, whose music was largely an adaptation and development of pre-existing blues and folk conventions. This became, according to Cope's taxonomy, heavy rock, while Black Sabbath invented a whole new musical form, heavy metal. While Zeppelin used conventional forms such as the blues scale, 12 bar forms, and gender anxiety-based lyrics, Sabbath pioneered a wholly new musical form. Thus, Cope has referred to Sabbath as 'the progenitors of heavy metal through the evolutionary formation of a specific set of musical and aesthetic principles which set them apart' (2010: 95). Bremer \& Cohniz echo this viewpoint, describing Deep Purple as 'a predictable development of earlier blues rock' and Led Zeppelin as a predictable result of a combination of folk and blues rock, while ‘Sabbath was an unpredictable creative breakthrough' (2013: 92).

\section{References}

Alexander. P. (2013), 'Tales of ordinary madness,' Mojo, June 2013, pp. 66- 79. 
Armstrong, A. C. (2008), 'The fragility of group flow: The experiences of two small groups in a middle school mathematics classroom.' The Journal of Mathematical Behavior, 27(2), pp. 101-115. Barnett, B. (2017), 'Black Sabbath’s pioneering lyrical rhetoric: Tragic structure and cathartic potential in song narratives', Metal Music Studies, 3:1, pp._81-96.

Berger, H. M. (1999), Metal, rock, and jazz. Perception and the phenomenology of musical experience, Hanover, N.H.: University Press of New England.

Black Sabbath (1970), 'Paranoid', Paranoid, Burbank, CA: Warner Brothers Records.

Black Sabbath (1972), 'Wheels of Confusion', Volume 4, Burbank, CA: Warner Brothers Records. Bremer, M. \& Cohnitz, D. (2013), ‘Saint Vitus dance: The art of doom', in W. Irwin (ed.), Black Sabbath \& Philosophy: Mastering Reality, West Sussex: Wiley-Blackwell, pp. 87-95.

Chirico, A., Serino, S., Cipresso, P., Gaggioli, A. \& Riva, G. (2015), 'When music "flows". State and trait in musical performance, composition and listening: a systematic review,' Front Psychol. 2015;6:906. Published 2015 Jun 30. doi:10.3389/fpsyg.2015.00906

Cope, A. L. (2010), Black Sabbath and the Rise of Heavy Metal Music, Burlington, VT: Ashgate.

Croom, A. M. (2012), 'Music, neuroscience, and the psychology of well-being: a précis.' Front. Psychol. 2:393. doi: 10.3389/fpsyg.2011.00393

Crosby, D. (1988), Long Time Gone: The Autobiography of David Crosby, New York, NY:

Doubleday

Csikszentmihalyi, M. (1990), Flow: The Psychology of Optimal Experience, New York: Harper Collins.

Engeser, S. (2012), Advances in flow research, New York: Springer.

Froese, B. (2013), 'Black Sabbath's apocalypse of horror', in W. Irwin (ed.), Black Sabbath \& Philosophy: Mastering Reality, West Sussex: Wiley-Blackwell, pp. 20-30.

Gaggioli A., Riva, G., Milani, L. \& Mazzoni, E. (2013b), 'Networked Flow: Towards an Understanding of Creative Networks,' Dordrecht: SpringerBriefs in Education; 10.1007/978-94007-5552-9

Gillett, C. (1994), The Sound of the City, London: Souvenir Press.

Hart, E., and Di Blasi, Z. (2015), 'Combined flow in musical jam sessions: a pilot qualitative study,' Psychol. Music. 43, pp. 275-290. doi: 10.1177/0305735613502374 van den Hout, J., Davis, O. \& Weggeman, M.C.D.P. (2018). 'The Conceptualization of Team Flow,' The Journal of Psychology, 152:6, pp. 388-423, DOI: $\underline{\text { 10.1080/00223980.2018.1449729 }}$ Herbst, J-P. (2017), 'Historical development, sound aesthetics and production techniques of the distorted electric guitar in metal music', Metal Music Studies, 3:1, pp. 2346. https://doi.org/10.1386/mms.3.1.23_1 
Hook, P. (2012), Unknown pleasures: Inside Joy Division, London: Simon and Schuster.

Iommi, T. (2012), Iron Man: My Journey Through Heaven and Hell with Black Sabbath, London: Simon \& Schuster.

Jackson, S. A. (1995), 'Factors influencing the occurrence of flow state in elite athletes.' Journal of Applied Sport Psychology, 7(2), pp. 138-166. doi:10.1080/10413209508406962

Joy Division, (1980), 'Passover', Closer, Manchester, Factory Records, Joy Division, (1980), 'Twenty Four Hours', Closer, Manchester, Factory Records, Lashua, B., Spracklen, K. \& Wagg, S. (Eds.) (2104), Sounds and the City, Basingstoke: Palgrave Macmillan.

Lucas, H. E. (2018), 'Social flow: Optimal experience with others at work and play,' in M. A. Warren \& S. I. Donaldson (Eds.), Toward a positive psychology of relationships: New directions in theory and research, pp. 179-192, Westport, CT: Praeger.

Male, A. (2020), 'Requiem', Mojo, February 2020, pp. 78-82.

McCready, J., 'On the passage of a few persons through a rather brief period of time,' Dazed and Confused, January 2002, pp. 90-99.

McIver, J. (2006), Sabbath Bloody Sabbath, London: Omnibus Press.

McIver, J. (2013), 'Black Sabbath and the sound of evil,'in W. Irwin (ed.), Black Sabbath \&

Philosophy: Mastering Reality, West Sussex: Wiley-Blackwell, pp. 33-40.

Morley, P. (2016), Joy Division: Piece by Piece, London: Plexus.

Morris, S. (2019), Record, Press, Play, London: Constable

Mynett, M. (2013), Contemporary Metal Music Production, PhD thesis, University of Huddersfield. Nevarez, L. (2013). 'How Joy Division came to sound like Manchester: Myth and ways of listening in the neoliberal city', Journal of Popular Music Studies, 25:1, pp. 56-76

Osbourne, O. (2010). I Am Ozzy, London: Sphere.

Pepper, K. (2013), ‘Tony Iommi's hand of doom: From plastic fingertips to creative freedom,' in W. Irwin (ed.), Black Sabbath \& Philosophy: Mastering Reality, West Sussex: Wiley-Blackwell, $51-60$.

Quinn, R. W. (2005), 'Flow in knowledge work: High performance experience in the design of national security technology.' Administrative Science Quarterly, 50(4), pp. 610-641. doi:10.2189/asqu.50.4.610

Russell, W. (2001), 'An examination of flow state occurrence in college athletes.' Journal of Sport Behaviour, 24(1), pp. 83-107.

Savage, J. (1979), 'Joy Division: Unknown Pleasures,' (album review), Melody Maker 21 July 1979.

Savage, J. (2005), England's Dreaming, London: Faber \& Faber. 
Sawyer, R. K. (2003), Group creativity: Music, Theater, Collaboration, Mahwah, NJ:

Lawrence Erlbaum Associates.

Sawyer, R. K. (2006), 'Group creativity: musical performance and collaboration.' Psychol.

Music, 34, pp. 148-165. doi: 10.1177/0305735606061850

Sawyer, R. K. (2007), Group Genius: The Creative Power of Collaboration, New York: Basic

Books.

Sharman, L. and Dingle, G. A. (2015), 'Extreme metal music and anger processing', Frontiers in Human Neuroscience, 9, pp. 1-11.

Sumner, B. (2014), Chapter and Verse, London: Corgi Books.

Hackman, J. R., \& Wageman, R. (2005), A Theory of Team Coaching. Academy of Management Review, 30, pp. 269-287. http://dx.doi.org/10.5465/AMR.2005.16387885

Walker, C. J. (2010), 'Experiencing flow: Is doing it together better than doing it alone?', The Journal of Positive Psychology, 5, pp. 3-11.

Wall, M. (2014), Black Sabbath: Symptom of the Universe, London: Orion House.

Walser, R. (1993), Running with the Devil: Power, Gender, and Madness in Heavy Metal Music, Middletown, CT: Wesleyan University

Williamson, N. (2005), 'Joni Mitchell: The deceptively ingenious folk innovator who reinvented tuning', Uncut Legends: The Hundred Greatest Guitar Heroes, pp. 40-42. 